\title{
GOL - REALIZANDO DESEJOS DE CONSUMO, UMA ANÁLISE DISCURSIVA SOBRE A “LIBERDADE” E O “QUERER”
}

\author{
GOL - ACCOMPLISHING CONSUMER'S WISHES, A DISCURSIVE ANALYSIS ON “FREEDOM” AND \\ "DESIRES"
}

\author{
Luciano Luiz ARAUJO \\ Universidade Federal de Alagoas \\ lucianolaraujo@gmail.com \\ Daniela Botti ROSA \\ Universidade Federal de Alagoas \\ dani.botti@hotmail.com
}

Resumo: Neste artigo, Sob a perspectiva da Análise do Discurso francesa, inaugurada por Michel Pêcheux, analisamos o discurso do editorial da Revistinha Gol no 1, distribuída aos passageiros da empresa aérea; para tal, convocamos à discussão ideias de Marx e Freud. A publicação destina-se ao público infantil para um momento de distração e lazer durante a viagem, porém parte de seu conteúdo, de certa forma, está direcionado ao público adulto. Dito isso, verificamos as contradições existentes nesse discurso estabelecidas entre pais/filhos na relação de consumo pretendida; a circulação de sentidos que giram em torno de ideias sobre a liberdade (de viajar de avião) e o querer (viajar de avião), bem como elementos utilizados para uma educação cultural para "formar" futuros consumidores. Entendemos que o discurso parte dos interesses da classe dominante, busca mostrar uma cultura do mundo moderno (a de viajar de avião) e que todos são autônomos e livres o suficiente, mesmo as crianças. Entendemos que se trata de uma pseudo autonomia e liberdade, porém, são estratégias para atingir interesses, e isso não se dá sem conflito, pois tais serviços aéreos não são para todos; eles custam um preço, é necessário ter moeda para comprá-los; por consequência, implica dizer: o dinheiro não veio do nada; custou ganhá-lo.

Palavras-chave: Discurso. Sujeito. Desejo. Ideologia. Empresa aérea.

Abstract: In this article, from the perspective of the French Discourse Analysis inaugurated by Pêcheux, we analyzed the speech of the editorial of the comic magazine Gol no 1 , distributed to the passengers of the airline company; to this end, we call on the ideas and discussion of Marx and Freud. The publication is aimed at children for a moment of distraction and relaxation during the trip, but some of its content, in a certain way, is directed at adults. That being said, we investigate the existing contradictions in this discourse established between parents / children in the relation of desired 
consumption; the circulation of meanings that revolve around ideas about freedom (to travel by plane) and the desire (travel by plane), as well as elements used for a cultural education to "educate" future consumers. We understand that the discourse comes from the interests of the ruling class, it seeks to show a culture of the modern world (to travel by plane) and that we all are independent and free enough, even children. We understand that it is about a pseudo autonomy and freedom, however, they are strategies to achieve interests, and this is not without conflict, because such air services are not for everyone; they cost a price, you must have money to buy them; consequently, that means: the money did not come from nowhere; it costs earning it.

Keywords: Speech. Subject. Wish. Ideology. Airline company.

Introdução - Um breve percurso histórico

[...] - É, o que é dinheiro, pai? [...] Dinheiro mesmo é aquilo que ele pode comprar; aquilo que custou ganhá-lo.

(PILAGALLO, 2009)

Neste trabalho, sob a perspectiva da Análise do Discurso francesa, inaugurada por Michel Pêcheux, nosso objetivo é analisar o discurso do editorial da Revistinha Gol n¹, distribuída aos passageiros da empresa aérea. Utilizar-nos-emos, para isso, de um diálogo com ideias de Freud e Marx. Embora direcionada ao público infantil, pressupomos que a revista pretende atingir outro público, assim, buscaremos verificar as contradições existentes nesse discurso, investigando como se dá a circulação de sentidos Abordaremos, em específico, aqueles que giram em torno de ideias sobre a liberdade e o querer; e como é estabelecida a conexão entre pais e filhos na relação de consumo pretendida.

Desejar, querer, sentir-se livre e autônomo são alguns dos sentidos que circulam na sociedade capitalista. Porém, tais sentimentos não são novos, vêm desde uma época remota, quando o homem primitivo lutava por sua sobrevivência. E essa luta implicava, necessariamente, em uma busca de dominação da natureza pelo homem; podemos ver isso por ocasião da descoberta do fogo, quando o homem disputou o domínio desse elemento. 
No decorrer da história das civilizações, o cozimento de alimentos surge enquanto atividade que sugere a utilização de instrumentos, como fogão, gás etc. Fazendo valer o domínio do fogo para a objetividade material. Com isso, concordamos com a seguinte afirmação:

O único pressuposto no pensamento de Marx é o fato de que os homens, para poderem existir, devem transformar constantemente a natureza. Essa é a base ineliminável do mundo dos homens. Sem a sua transformação, a reprodução da sociedade não seria possível. Essa dependência da sociedade para com a natureza, contudo, não significa que o mundo dos homens esteja submetido às mesmas leis e processos do mundo natural. Sem a reprodução biológica dos indivíduos não há sociedade; mas a história dos homens é muito mais do que a sua reprodução biológica. A luta de classes, os sentimentos humanos, ou mesmo uma obra de arte, são alguns exemplos que demonstram que a vida social é determinada por outros fatores que não são biológicos, mas sociais. (LESSA, TONET, 2008, p.17)

Isso posto, é do nosso entendimento que o mundo social se apresenta em constantes mudanças, compreendemos que as relações sociais mudam conforme os desejos, seguindo a um modo de produção; e tais desejos mudam de acordo com as necessidades. Inferimos que as necessidades postas pelo "mundo dos homens" (LESSA, TONET, 2008, p.17) colocam para o homem o pressuposto de uma possível liberdade, quando saciadas ou na busca de saciá-las.

Umas dessas "necessidades", também vista como sonho, é a vontade de voar como os pássaros, imitá-los em seu gesto singular. E isso, posteriormente, ganha contornos científicos na busca de sua realização. A esse respeito, vemos na História registros sobre métodos reais que o homem utilizou para ganhar asas e "vencer" a gravidade. No Brasil, temos Santos Dumont, que realizou seu primeiro voo no aeroplano 14 bis, no entanto é relevante dizer,

Antes de Santos-Dumont, outros aeronautas já haviam realizado experiências com máquinas mais pesadas que o ar. O grande problema por eles não resolvido era a força propulsora inicial, necessária à decolagem. No caso dos irmãos Wright, seus vôos foram iniciados com auxilio de catapulta ou fazendo o aeroplano deslizar por um longo plano inclinado. (ITAÚ CULTURAL, 1996, p11)

A partir daí surgem inovações no modelo da aeronave; e esse meio de transporte, devido a uma necessidade da sociedade, com a premissa de transformar "tempo em dinheiro", passa a ser bastante utilizado, "diminuindo distâncias" entre 
localidades. Nesse contexto, ao longo dos anos, empresas surgem para explorar esse novo nicho de mercado. Entre as credenciadas para explorar o espaço aéreo brasileiro está a GOL, que ao longo dos anos tem se consolidado como uma importante empresa.

\section{Sujeito, língua e linguagem}

A AD, fundada na França por Michel Pêcheux, segundo Cavalcante (2007), assenta-se em dois conceitos nucleares - ideologia e discurso - e constitui uma teoria crítica da linguagem. Nessa perspectiva, a língua não é homogênea e está sujeita à intervenção humana, social e histórica; portanto, a linguagem do sujeito é vista como objeto discursivo, sócio-histórico, ideológico e sujeito às várias interpretações. Segundo Orlandi (2003, p. 15-6),

A Análise do Discurso não trabalha a língua como sistema abstrato, mas com a língua no mundo, com maneiras de significar, com homens falando, considerando a produção de sentidos enquanto parte de suas vidas, seja enquanto sujeitos, seja enquanto membros de uma determinada forma de sociedade.

O concreto que se apresenta na língua, considerando nossa perspectiva teórica, está ligado aos vários sentidos que a linguagem assume historicamente nas relações sociais. Daí é que surge a necessidade de verificarmos os sentidos que estão circulando no discurso do editorial da Revistinha Gol no1, os quais remetem ao querer e à ideia de sentir-se livre, como podemos perceber através da análise da materialidade discursiva que se segue: 


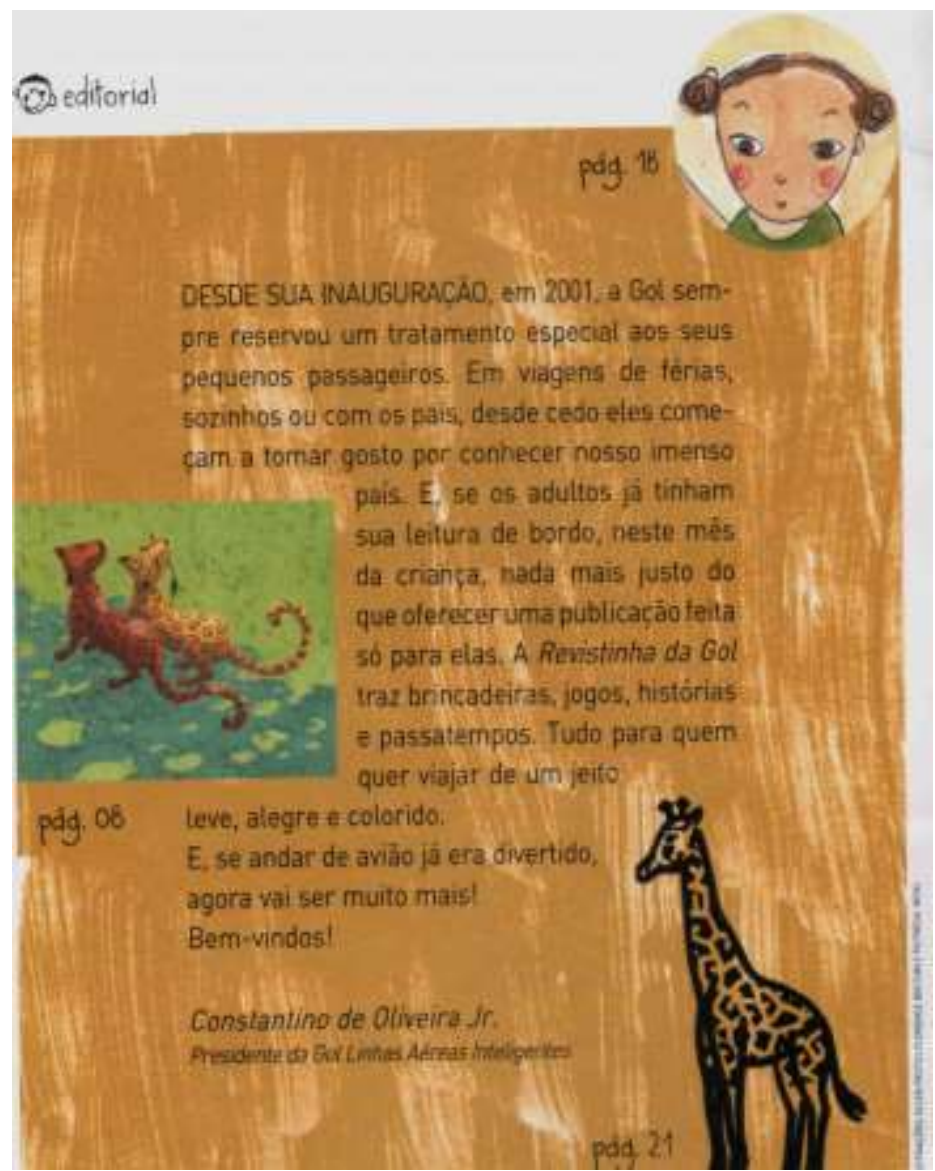

Figura 1 - Editorial da Revistinha Gol nº 1.

Fizemos a opção por apresentar a materialidade discursiva tal como se apresenta na revista, porque ela se mostra com um diferencial, com a ilustração que a direciona para o público infantil. Como a materialidade reporta a um universo infantil, iniciaremos nossa análise apresentando como compreendemos a entrada do discurso por este universo.

Segundo Althusser,

Foi a partir de Freud que começamos a suspeitar do que escutar, logo do que falar (e calar) quer dizer: que este "quer dizer" do falar e do escutar descobre, sob a inocência da fala e da escuta, a profundeza determinada de um fundo duplo do qual a linguística moderna, nos mecanismos da linguagem, pensa os efeitos e condições formais. (ALTHUSSER apud MARIANI, 2010, p.117) 
Entendemos a linguagem enquanto praxis social, considerando a exterioridade como constitutiva. E, sendo o discurso o ponto mediador entre o homem e sua realidade social, tal práxis vem carregada de uma ideologia do sujeito, inerente ao contexto socio-histórico. Pois,

Todo discurso é ideológico, uma vez que, ao produzi-lo, o sujeito o faz a partir de um lugar social, de uma perspectiva ideológica, e assim veicula valores, crenças, visões de mundo que representam os lugares sociais que ocupa. O discurso é, pois, campo de mediações que articula novos sentidos ao já conhecido. Ele tem a capacidade de (re)significar o já dito e instituir uma nova memória discursiva. (CAVALCANTE, 2007, p.35).

Tomamos como premissa que o sujeito do discurso é constituído na e pela linguagem, com isso, concordamos que o sujeito se dá no e pelo discurso. Segundo Orlandi (2003), ele funciona pelo inconsciente e pela ideologia, em um discurso que vem marcado pelo contexto sócio-histórico, pois somente há sentido porque a linguagem se inscreve na história:

A linguagem, como a consciência, é, pois, um fato social, uma vez que resulta do processo de apropriação-objetivação dos produtos humanos historicamente acumulados. [...] É através da linguagem que os indivíduos se apropiam da realidade e da própria linguagem, de conceitos que Ihes permitem entender os fenômenos e agir no mundo. Essa forma de objetivação se objetiva via discurso. (CAVALCANTE, 2007, p.136)

Nesse sentido, as condições de produção do Editorial analisado foram estabelecidas por ocasião do discurso ter sido materializado em uma revista impressa da Empresa GOL. A materialidade discursiva encontra-se na página 4 dessa publicação, que dialoga com outros ditos e imagens que se encontram nas páginas 5 , 6 e 7, pois elas reforçam o discurso do editorial. Sobre essa categoria, utilizamos o conceito de Melo, quando ele explicita que o "Editorial é o gênero jornalístico que expressa a opinião oficial da empresa diante dos fatos de maior repercussão no momento" (2003, p.103). Ainda sobre o editorial, diz o pesquisador:

[...] Nas sociedades capitalistas, o editorial reflete não exatamente a opinião dos seus proprietários nominais, mas o consenso das opiniões que emanam dos diferentes núcleos que participam da propriedade da organização[...] afigura-se como um espaço de contradições. Seu discurso constitui uma teia de articulações políticas e por isso representa um exercício permanente de equilíbrio semântico. Sua vocação é a de apreender e conciliar os diferentes interesses que perpassam sua operação cotidiana[...] Não se trata de uma atividade voltada para perceber as reivindicações da coletividade e expressá-las a quem de direito. Significa muito 
mais um trabalho de "coação" ao estado para a defesa de interesses dos segmentos empresariais e financeiros que representam. (MELO, 2003, p.104-105)

Embora Melo afirme que o editorial parte de uma publicação jornalística para a coletividade, com temáticas que envolvem o Estado, o que percebemos nesta materialidade é que ela, sendo publicada em um espaço dedicado ao entretenimento, serve de propaganda para a empresa.

O editorial, no caso analisado, objetiva explicar a revista, porém questões outras vêm à tona, como veremos no decorrer da análise da referida materialidade.

\section{O discurso da GOL - 0 querer e o conceito de liberdade postos nas relações sociais}

A ideologia materializa-se na linguagem. Dito isso, não há um discurso em que a ideologia não esteja presente. Por ideologia entendem-se as posições assumidas pelos sujeitos em diferentes práticas sociais, as quais veiculam valores, crenças religiosas, culturais e políticas do sujeito, e que passam a identificá-lo na sociedade. Verificamos em Magalhães que "a subjetividade que percebe carências precisa conhecer a legalidade da objetividade para nela interferir, mas apenas dentro das possibilidades permitidas por essa mesma objetividade" (MAGALHÃES, 2005, p.28); pois "é o surgimento da subjetividade que instaura o ser social; e a história do gênero humano é a história da intervenção da subjetividade na objetividade. É nessa relação que se consubstancia a força do sujeito." (MAGALHÃES, 2005, p.28).

Se "a língua produz sentidos por/para sujeitos" (ORLANDI, 2003, p.17), a questão a ser verificada nos domínios da $A D$ é de que forma o discurso significa, já que ele está inscrito na história, através da linguagem e da ideologia do sujeito, uma vez que sustentamo-nos nesse entendimento, de materialização da ideologia na linguagem/discurso do sujeito, que perpassa o sócio-histórico.

Dito isso, entendemos que o ser humano é cheio de desejos e faltas; homens e mulheres postos em uma arena, na qual o que vale é a superação desses sentimentos. Nessa arena, ambos compartilham a palavra e sua práxis social; é nela, por e através dela, que os conflitos e contradições são postos. Com isso em vista, trazemos à 
discussão os pensamentos de Marx, pois, na relação social, as contradições e conflitos existentes estão embasados na relação entre a infraestrutura - em que percebemos a relação entre homem/natureza e homem/homem - e superestrutura - base ideológica de um determinado sistema de produção; ambas se inter-relacionam dialeticamente com a visão marxista, pois a mesma

não se limita à "natureza" e as suas leis, mas engloba as próprias condições nas quais o "homem" como parte da natureza entra em relação com elas, isto é, as forças produtivas e as relações de produção que determinan a história das "sociedades humanas", com a luta de classes que lhe corresponde - e as forças materias colocadas, assim em jogo - desde o início dessa história. O ideológico, enquanto "representação" imaginária, está por essa razão, necessariamente subordinado às forças materias "que dirigem os homens. (PÊCHEUX, 1988, p.73)

Entendemos que desde a infância o gênero humano é educado para proceder de acordo com comportamentos "predeterminados" pela sociedade que vive; e isso implica necessariamente na interpelação dos indivíduos como sujeitos, pois "supõe a "existência" de um Outro Sujeito, Único, e central, em Nome do qual a ideologia interpela todos os indíviduos como sujeitos." (ALTHUSSER, 1985, p.101). Seja o gênero feminino ou masculino, em diferentes classes sociais, modelos diferentes de conduta são postos. Nesse caso, os valores culturais e a história têm papéis fundamentais na reprodução do pensamento ideológico, posto nessa relação, pois tal pensamento é transmitido de geração a geração, no intuito do favorecimento de determinada classe ou grupo.

Visto que a reprodução se dá através do discurso, pois "todo processo discursivo se inscreve numa relação ideológica de classes" (PÊCHEUX, 1988, p.92); compreendemos que a criança é tomada pelo significante do outro. Portanto, quando o editorial diz: Começam a tomar gosto por conhecer nosso imenso país; vemos essa tomada do significante do "outro" ganhar forma através dos processos conscientes e inconscientes da criança, criando todo um imaginário. Esse enunciado liga o "outro", sujeito, ao desejo posto pelo "Outro" o que implicaria em uma possível ideia de autonomia dos pequenos passageiros.

São as relações sociais de consumo que pretendem criar estas concepções ou 
conceitos de liberdade e autonomia para as crianças, assim, reforçam os desejos de consumo, e mais que isso, nos revelam um discurso, que se mostra, segundo Althusser em sua leitura sobre Freud e Lacan,

[...] Da Ordem do significante humano, quer dizer da Lei da Cultura; este discurso, condição absoluta de qualquer discurso, este discurso presente de cima, ou seja, ausente em seu abismo, em qualquer discurso verbal, o discurso dessa ordem, esse discurso do Outro, do grande Terceiro, que é essa Ordem mesma: o discurso do inconsciente. Por aí nos é dada uma captação, conceitual, do inconsciente, que é, em cada ser humano, o lugar absoluto no qual seu iscurso singular busca seu próprio lugar, busca, fracassa nessa busca, e assim fracassando, encontra 0 seu próprio lugar, a ancôra própria do seu lugar, na imposição, na impostura, na cumplicidade e na denegação se seus próprios fascínios imaginários. (ALTHUSSER, 1984, p.67)

Nas páginas seguintes da revistinha, vemos fotos que reforçam a ideia apresentada no discurso do editorial (figura 1).

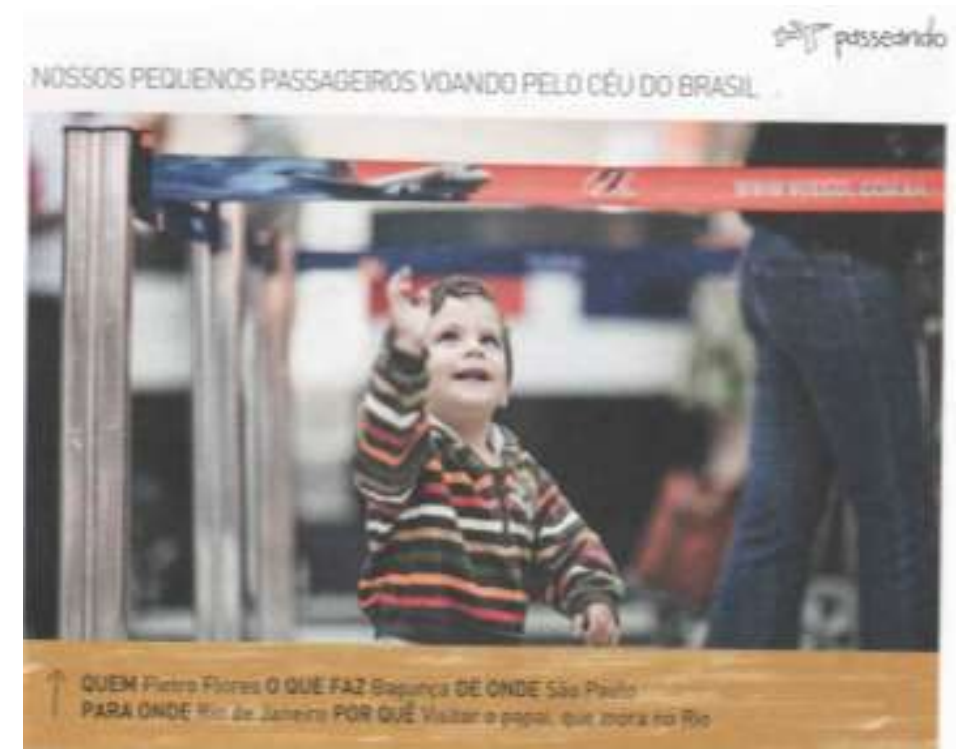

Figura 2 - Revistinha da Gol, número 1, página 5. 


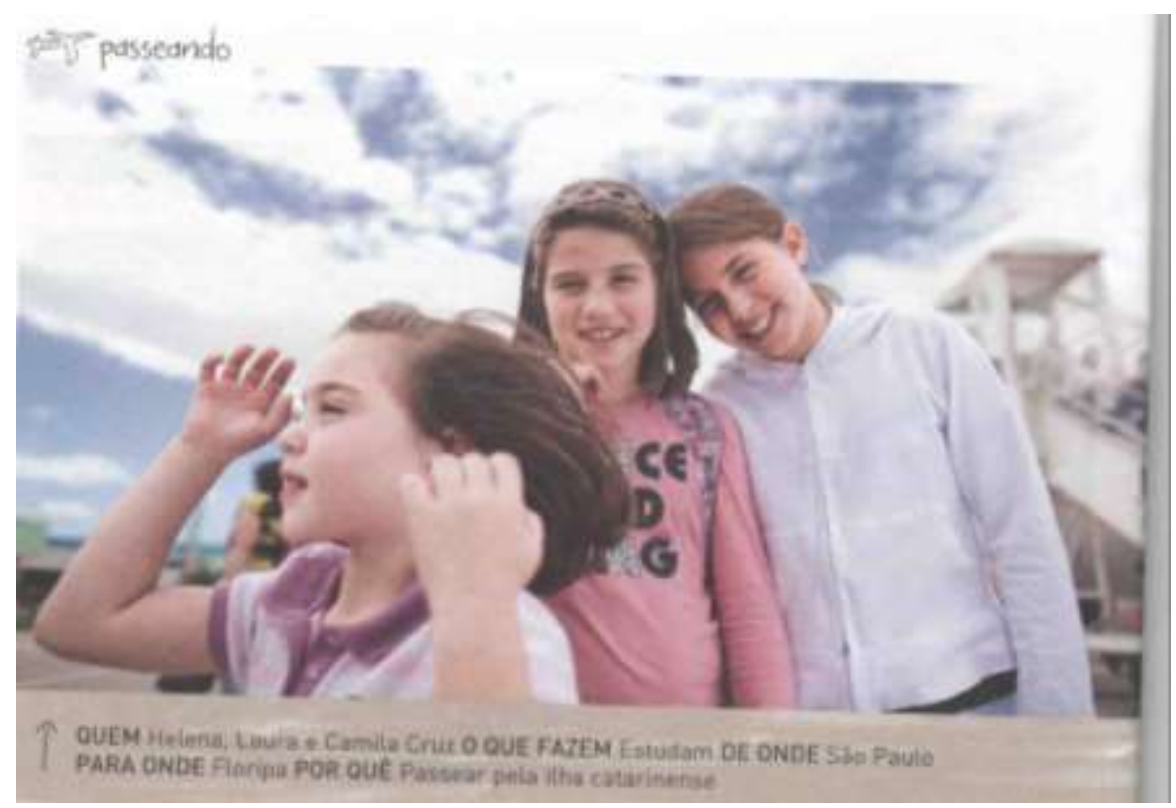

Figura 3 - Revistinha da Gol, número 1, página 6.

Nas duas imagens que selecionamos (figuras 2 e 3), percebemos o reflexo do que está sendo colocado no editorial, um tratamento especial aos seus pequenos passageiros, ao mesmo tempo que refrata uma realidade. O que se coloca de representação das crianças é que elas já estão sendo tratadas como adultos; pessoas livres e autônomas. Trata-se de uma derivação do discurso, que busca um efeito de evidência.

Enfatizamos, nas fotos apresentadas na revista, a representação de crianças felizes pela realização da viagem com a empresa aérea; contudo não há a presença de nenhuma criança negra. Isso revela a existência de muitas outras discursividades ali se processando, a exemplo de questões raciais, pois se silencia a possibilidade de que produto ofertado esteja ao alcance do público negro, um efeito de evidência ideológico que apenas crianças brancas e ricas teriam a possibilidade de consumir tal produto.

Tomemos outra sequência para nossa discussão: Tudo para quem quer viajar de um jeito leve, alegre e colorido. 
Vemos nessa sequência discursiva que o Sujeito busca incitar no outro o desejo do "querer", e percebemos que existe o diálogo com um discurso recorrente em nossa sociedade, o qual, "querer é poder". Não haveria limites para o outro sujeito (consumidor) na realização de sua "liberdade", viajando de um jeito leve, alegre e colorido.

Isso posto, fazemos alguns apontamentos:

a) A criança é vista como um adulto consumidor em potencial; como sujeito que tem desejos e vontades os quais precisam ser realizados. Nessas condições, viajar de avião torna-se possível de realização, desde que o indivíduo adulto financie tal viagem, mediada pela empresa Gol, a esse respeito, entendemos, consoante Althusser, que

"O desejo, categoria fundamental do inconsciente, só é intelegível em sua especificidade como o sentido singular do discurso do inconsciente do sujeito humano: o sentido que surge no "jogo" e pelo "jogo" a cadeia significante de que se compõe o discurso do inconsciente. (1984, p.66)

b) Percebemos o pressuposto de que, se a criança quer viajar de um jeito "leve, alegre e colorido", a Gol transformará seus desejos em realidade (uma viagem dos sonhos), sendo esta viagem figurada como uma brincadeira de criança, o que reforça a ideia de autonomia, considerando o pensamento de Freud de que o sujeito é "constituído por uma estrutura que também tem um "centro" apenas no desconhecimento imaginário do "eu", ou seja, nas formações ideológicas em que ele se "reconhece" (Althusser, 1984, p.71). Nesse sentido, o discurso busca que o sujeito venha se reconhecer no produto ofertado para então consumi-lo.

c) Para a Gol isso não implica em uma brincadeira. Na lógica capitalista, trata-se do mundo dos negócios, por isso "reservou um tratamento especial aos seus pequenos passageiros" - consumidores em potencial - embora os custos finaceiros do possível usufruto da viagem, sejam pagos por um adulto, em muitos casos os pais, ou parentes próximos.

$\mathrm{Na}$ tessitura deste discurso, compreendemos que quando se fala em viajar sozinhos (editorial), há um apagamento de determinada relação entre os sujeitos e a mercadoria. Ou seja, no caso de os pais ou responsáveis pela criança, por motivos 
diversos, porventura não puderem acompanhar o menor em sua viagem, a Gol se dispõe a dar o conforto necessário a esta criança, através da revista. Em um primeiro momento, e, de uma forma geral, subentende-se que seja possível que a criança viaje sozinha pela Gol, considerando os serviços oferecidos e que podem substituir momentaneamente a não presença dos pais/pessoa adulta. Acreditamos que nas viagens feitas pelas crianças, na maioria dos casos, a presença dos pais ou de adultos é notória; daí percebemos certo dilema paradoxal na ideia de liberdade que é passada para as crianças.

Voltemos à epígrafe de nosso trabalho, que foi retirada da crônica $O$ que é dinheiro? (PILAGALLO, 2009) Nessa crônica, o filho faz a pergunta à qual o pai, ao longo da crônica, tenta de várias maneiras responder. Uma de suas respostas é a que apresentamos: Dinheiro mesmo é aquilo que ele pode comprar; aquilo que custou ganhá-lo. Tal passagem nos ajuda a entender a materialidade discursiva analisada, quando percebemos que está colocada uma relação que envolve alguém que paga um salário (patrão), alguém que recebe (empregado) e as pessoas familiares(filhos) que estão ligados aos adultos em uma situação de dependência.

Com isso, a nossa compreensão é a de que o discurso posto atende aos interesses da classe dominante e visa atingir aos que são financeiramente capazes. Porém, a esse respeito, Marx faz crítica às noções de homo economicus e sujeitoconsciente.

Importante recordar que essa ideologia do sujeito-consciente constitui a filosofia implícita na teoria da Economia Política Clássica, e que foi sua versão econômica o que Marx criticou, ao recusar a noção de homo economicus, segundo a qual o homem se define como o sujeito-consciente de suas necessidades, e esse sujeito-de-necessidade, como elemento último e constitutivo de toda sociedade. (Althusser 1984, p.84)

Como afirmamos anteriormente, a sociedade e o modo de produção/ reprodução, criam os desejos e as necessidades do mundo capitalista. Um discurso que busca envolver o adulto e a criança, e, principalmente, visa educar a ambos para um hábito cultural - viajar de avião - consequentemente, sendo "parceiros" da companhia aérea.

Para finalizarmos a discussão, gostaríamos de comentar a foto da capa da revistinha, retomada nas páginas posteriores ao editorial, 


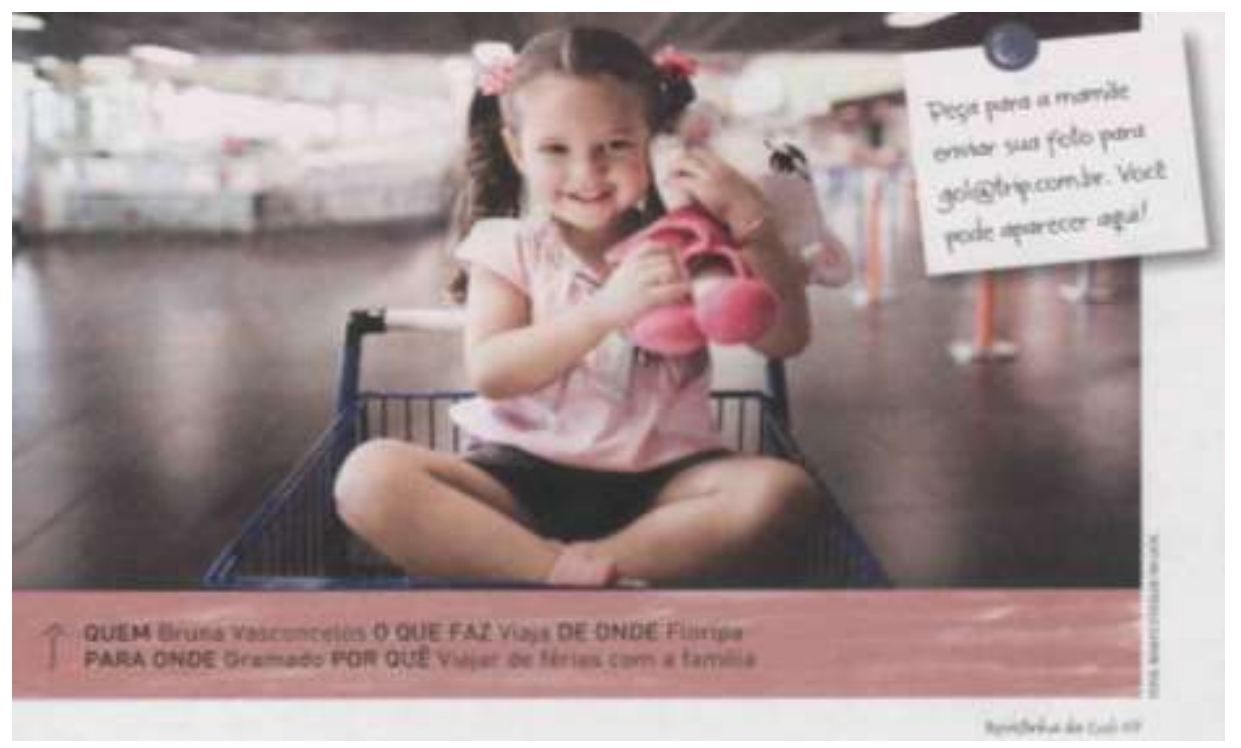

Figura 4 - Revistinha da Gol, número 1, página 7.

Nessa foto, percebemos uma criança feliz por viajar pela GOL com sua família, sugerindo que criança peça para a mãe enviar uma foto sua, pois assim poderá aparecer na revistinha. Ou seja, por um instante se tornará uma celebridade, por ter viajado pela empresa.

Concluímos que o discurso parte do mercado, que busca mostrar um hábito da sociedade atual (viajar de avião) e constrói a ideia de que todos são autônomos e livres o suficiente, mesmo as crianças. Nosso ponto de vista é que se trata de uma pseudo autonomia e liberdade, porém são estratégias para atingir seus interesses e isso não se dá sem conflito, pois os serviços aéreos não são para todos; eles custam um preço, é necessário ter moeda para comprá-los, e isso, por consequência, implica dizer, o dinheiro não veio do nada; custou ganhá-lo.

\section{Referências bibliográficas}

ALTHUSSER, L. Freud e Lacan, Marx e Freud: Introdução crítica-histórica. 2. Ed. Rio de Janeiro: Graal, 1984. 
Aparelhos Ideológicos de Estado: Nota sobre os Aparelhos Ideológicos de Estado. 2. Ed. Rio de Janeiro: Graal,1985.

BAKHTIN, M. Marxismo e filosofia da linguagem: problemas fundamentais do Método Sociológico na Ciência da Linguagem. 13. Ed. São Paulo: Hucitec, 2009.

CAVALCANTI, M. S. A. O. Qualidade e cidadania nas reformas da educação brasileira: o simulacro de um discurso modernizador. Maceió: EDUFAL, 2007

ITAÚ CULTURAL. Santos-Dumont. São Paulo: Itaú Cultural, 1996.

GOL TRANSPORTES AÉREOS. Revistinha da gol. São Paulo: Trip Editora e Propaganda, S/D.

LESSA, S., TONET, I. Introdução à Filosofia de Marx. São Paulo: Expressão Popular, 2008.

MAGALHÃES, B. As marcas do corpo contando a história: um estudo sobre a violência doméstica. Maceió: EDUFAL, 2005.

MARIANI, B. Sobre o sujeito e a língua em alguns textos e conceitos fundadores de m. Pêcheux: uma retomada em Althusser e Lacan. Alpha; Revista de Linguística. Araraquara, v. 54, n. 1, p.113-127, 2010.

MELO, J. M. de, Jornalismo opinativo no jornalismo brasileiro. 3 ed. rev. e ampl. Campos do Jordão: Mantiqueira, 2003.

ORLANDI, E. P. Análise de discurso: princípios e procedimentos. 5 ed. Campinas: Pontes, 2003.

PÊCHEUX, M. Semântica e discurso: uma crítica à afirmação do óbvio. Campinas: Editora da UNICAMP, 1988.

PILAGALLO, O. A aventura do dinheiro: uma crônica da história milenar da moeda. São Paulo: Publifolha, 2009.

PPGLL/UFAL. Ideologia e práticas discursivas. Leitura: Revista do Programa de PósGraduação em Letras e Linguística. Maceió: EDUFAL, n. 40, 2007. 